\title{
Impacts of different administration modes of dexmedetomidine with $0.5 \%$ ropivacaine on intercostal nerve block
}

\author{
Fei Yao, Shaojun Xu, Wenjing Zhang, Huaping Xiong, Jinfeng Han, Aibing Zhu \\ Department of Anesthesiology, Wuxi Maternity and Child Health Care Hospital Affiliated to Nanjing Medical University, Wuxi 214002, China \\ Contributions: (I) Conception and design: F Yao; (II) Administrative support: A Zhu; (III) Provision of study materials or patients: S Xu, W Zhang, H \\ Xiong; (IV) Collection and assembly of data: H Xiong; (V) Data analysis and interpretation: J Han; (VI) Manuscript writing: All authors; (VII) Final \\ approval of manuscript: All authors. \\ Correspondence to: Huaping Xiong. Department of Anesthesiology, Wuxi Maternity and Child Health Care Hospital Affiliated to Nanjing Medical \\ University, Wuxi 214002, China. Email: 8553228@qq.com.
}

\begin{abstract}
Background: To investigate the effectiveness and rationality of different administration modes of dexmedetomidine with $0.5 \%$ ropivacaine on intercostal nerve block.

Methods: In total, 150 patients aged from 20-45 years with a body mass index (BMI): $18.5-23.9 \mathrm{~kg} / \mathrm{m}^{2}$, met the criteria from the American Society of Anesthesiologists (ASA) class: I-II, and underwent lumpectomy in our center were equally randomized into three groups using a table of random numbers. Group D1: perineural administration of dexmedetomidine $0.5 \mu \mathrm{g} / \mathrm{kg}+$ intercostal nerve block with $0.5 \%$ ropivacaine; group D2: intravenous infusion of dexmedetomidine $0.5 \mu \mathrm{g} / \mathrm{kg}+$ intercostal nerve block with $0.5 \%$ ropivacaine; and group $\mathrm{R}$ : intercostal nerve block with $0.5 \%$ ropivacaine. The Numerical Rating Scale (NRS) of pain and the Ramsay Sedation Scale were used for assessing pain and sedation levels 4, 8, 12, and 24 hours after the operation. The total duration of analgesia, total requirement of rescue analgesia, and adverse reactions were recorded.
\end{abstract}

Results: The NRS scores in groups D1 and D2 were significantly lower than that in group R, 8 hours after the operation (both $\mathrm{P}<0.05$ ), and the NRS score in group D1 was significantly lower than in group D2 12 hours after the operation $(\mathrm{P}<0.05)$. The Ramsay scores showed no significant differences among all three groups at all time points after surgery. The duration of analgesia in group D1 was significantly longer than in group D2 $(\mathrm{P}<0.05)$. No rescue analgesia was needed in all three groups, and no adverse reactions such as dizziness, dry mouth, nausea, vomiting, and respiratory depression were reported.

Conclusions: The combinations of dexmedetomidine with ropivacaine for intercostal nerve blocking can prolong the duration of analgesia after lumpectomy; however, the duration of analgesia is longer via the perineural route than via the intravenous route.

Keywords: Dexmedetomidine; ropivacaine; intercostal nerve block; lumpectomy

Submitted Dec 20, 2019. Accepted for publication Feb 19, 2020.

doi: 10.21037/apm.2020.03.25

View this article at: http://dx.doi.org/10.21037/apm.2020.03.25

\section{Introduction}

The features of an intercostal nerve block are a simple operation, accurate effect, small impact on breathing, and stable hemodynamics. It is one of the commonly used anesthesia methods for lumpectomy $(1,2)$. Dexmedetomidine is a highly selective $\alpha_{2}$-adrenoreceptor agonist having multifaceted attributes of sedation, anxiolysis, hypnosis, analgesia, and sympatholysis (3). When combined with local anesthetics, it may improve regional block and intrathecal anesthesia $(4,5)$. In our current study, we compared the impacts of different administration modes of dexmedetomidine on the effectiveness of intercostal nerve block and the duration of postoperative analgesia, 
thus informing the rational use of clinical drugs.

\section{Methods}

\section{General data}

This study was approved by the Ethics Committee of Wuxi Maternity and Child Health Care Hospital, and all the subjects and their families signed the informed consent forms.

The inclusion criteria included: American Society of Anesthesiologists (ASA) class: I-II; age: $20-45$ years; body mass index (BMI): $18.5-23.9 \mathrm{~kg} / \mathrm{m}^{2}$; and undergoing elective lumpectomy. The exclusion criteria included: with severe heart, liver, kidney and/or blood system diseases; long-term user of sedative and analgesic drugs; and with a history of allergy to local anesthetics and/or alcoholism before surgery.

The patients were randomly divided into three groups by using a table of random numbers: group D1: perineural administration of dexmedetomidine $0.5 \mu \mathrm{g} / \mathrm{kg}+$ intercostal nerve block with $0.5 \%$ ropivacaine); group D2: intravenous infusion of dexmedetomidine $0.5 \mu \mathrm{g} / \mathrm{kg}+$ intercostal nerve block with $0.5 \%$ ropivacaine; and group R: intercostal nerve block with $0.5 \%$ ropivacaine.

\section{Anesthesia methods}

All patients fasted before surgery. After the patients entered the operating room, they were checked with an electrocardiogram (ECG) and their heart rate (HR), blood pressure (BP), and blood oxygen saturation $\left(\mathrm{SpO}_{2}\right)$ were measured. A face mask was applied for oxygen delivery at a rate of $3 \mathrm{~L} / \mathrm{min}$. Open venous channels were created to enable the compound sodium lactate infusion at a rate of $10 \mathrm{~mL} / \mathrm{kg}$ per hour. In group D1, perineural administration of $0.5 \mu \mathrm{g} / \mathrm{kg}$ dexmedetomidine (Hengrui Medicine, Jiangsu Province, China; lot number: 181230BP) + intercostal nerve block with $0.5 \%$ ropivacaine (Qilu Pharmaceutical; lot number: 8B132C35) was applied. In group D2, after successful intercostal nerve block with $0.5 \%$ ropivacaine, intravenous infusion of $0.5 \mu \mathrm{g} / \mathrm{kg}$ dexmedetomidine was applied till the end of surgery. Group $\mathrm{R}$ received the intercostal nerve block with $0.5 \%$ ropivacaine only. All patients underwent intercostal nerve block via the anterior axillary approach. The $T_{2}$ to $T_{6}$ intercostal space was selected. The needle was inserted perpendicularly at the intersection between the lower edge of the rib and the anterior axillary line. After the lower edge of the rib was reached, the needle was inserted downwards and inwards 3$5 \mathrm{~mm}$. If there was no blood or air return in the syringe, $5 \mathrm{~mL}$ of anesthetic solution was injected. Four intercostal nerves were blocked simultaneously according to the location of the mass. If the intercostal nerve block was inadequate, conversion to general anesthesia was needed, and the patients were ruled out from the study. If the intraoperative mean arterial pressure (MAP) decreased and the fluctuation range was greater than $30 \%$ of the basal value, intravenous injection of ephedrine $10 \mathrm{mg}$ was needed. If the HR was below $50 \mathrm{bpm}$, intravenous injection of atropine $0.5 \mathrm{mg}$ was applied. If the $\mathrm{SpO}_{2}$ was $<90 \%$, maskassisted ventilation was given. After the surgery, a single intravenous injection of tramadol $1-2 \mathrm{mg} / \mathrm{kg}$ would be applied for rescue analgesia if the patients required.

\section{Main measures}

The main measures included: NRS scores ( 0 representing no pain and 10 representing worst pain) and Ramsay sedation scores (1 point: not quiet, agitated patients; 2 points: quiet and cooperative patients; 3 points: drowsy and obeying directive; 4 points: drowsy and responding to tactile stimulation; 5 points: lethargic and only responding to strong stimulation; 6 points: in deep sleep, no response to calling; a score of 1 means unsatisfactory sedation, 2-4 means satisfactory sedation, and 5-6 means excessive sedation); duration of postoperative analgesia; number of cases requiring rescue analgesia; and adverse reactions such as dizziness, dry mouth, nausea, vomiting, and respiratory depression.

\section{Statistical analysis}

Statistical analysis was performed using SPSS 17.0 software. The measurement data were expressed as mean \pm standard deviation $(\bar{x} \pm S D)$, and the inter-group comparisons were performed using one-way ANOVA. Comparisons of count data were performed using the chi-square test, with a $\mathrm{P}$ value of less than 0.05 being considered statistically significant.

\section{Results}

The ASA classification, age, and BMI were matched among these three groups.

The NRS scores in groups D1 and D2 were significantly 
Table 1 Comparisons of NRS scores and Ramsay scores among three groups (points, $\bar{\chi} \pm$ SD)

\begin{tabular}{|c|c|c|c|c|c|c|}
\hline Items & Group & $\mathrm{n}$ & $4 \mathrm{~h}$ after surgery & $8 \mathrm{~h}$ after surgery & $12 \mathrm{~h}$ after surgery & $24 \mathrm{~h}$ after surgery \\
\hline \multirow{2}{*}{ NRS score } & Group D2 & 50 & $1.3 \pm 1.0$ & $1.8 \pm 1.2^{\mathrm{a}}$ & $4.0 \pm 1.5$ & $1.5 \pm 1.1$ \\
\hline & Group R & 50 & $1.5 \pm 1.1$ & $4.4 \pm 1.5$ & $4.2 \pm 1.6$ & $1.9 \pm 1.2$ \\
\hline \multirow[t]{2}{*}{ Ramsay score } & Group D1 & 50 & $2.6 \pm 0.6$ & $2.8 \pm 0.5$ & $3.2 \pm 0.3$ & $3.0 \pm 0.5$ \\
\hline & Group R & 50 & $2.9 \pm 0.4$ & $3.0 \pm 0.4$ & $3.5 \pm 0.6$ & $3.1 \pm 0.5$ \\
\hline
\end{tabular}

${ }^{a}, \mathrm{P}<0.05$, compared with group $\mathrm{R} ;{ }^{\mathrm{b}}, \mathrm{P}<0.05$, compared with group D2. NRS, Numerical Rating Scale.

lower than that in group R 8 hours after the operation (both $\mathrm{P}<0.05$ ), and the NRS score in group D1 was significantly lower than in group D2 12 hours after operation $(\mathrm{P}<0.05)$. The Ramsay scores showed no significant differences among all three groups at all time points after surgery (Table 1).

The duration of postoperative analgesia was significantly longer in groups D1 $[(14.2 \pm 1.2) \mathrm{h}]$, and D2 $[(9.0 \pm 0.6) \mathrm{h}]$ in group $\mathrm{R}[(7.1 \pm 0.4) \mathrm{h}]$ (both $\mathrm{P}<0.05)$, and group D1 also had significantly longer duration of postoperative analgesia than in group $\mathrm{D} 2(\mathrm{P}<0.05)$.

No rescue analgesia was needed in all three groups, and no adverse reactions such as dizziness, dry mouth, nausea, vomiting, and respiratory depression were reported.

\section{Discussion}

Regional anesthesia has increasingly become popular among surgeons and patients with the development of enhanced recovery after surgery (ERAS) and comfort medicine. An intercostal nerve block is widely used in lumpectomy due to its simplicity and definite analgesic effect. Ropivacaine is a long-acting amide local anesthetic agent. It is thought to provide greater separation of sensory and motor effects, with fewer cardiac toxicities. However, ropivacaine alone has a short duration when used for nerve block and its role in postoperative analgesia is limited; thus, it is not possible for ERAS and comfort medicine to work together.

Dexmedetomidine is a highly selective $\alpha_{2}$-adrenergic receptor agonist. It is 1,600-fold more selective for $\alpha_{2}$ receptor than for a 1 receptor and has an elimination half-life of 2 to 3 hours (3). Studies have found that the combination of dexmedetomidine and ropivacaine can enhance the effects of peripheral nerve block and prolong the duration of sensory block $(6,7)$. In our current study, intravenous infusion of dexmedetomidine $0.5 \mu \mathrm{g} / \mathrm{kg}$ combined with intercostal nerve block with $0.5 \%$ ropivacaine achieved longer postoperative analgesia duration $[(9.0 \pm 0.6) \mathrm{h}]$, which was significantly longer than that $[(7.1 \pm 0.4) \mathrm{h}]$ of intercostal nerve block with $0.5 \%$ ropivacaine alone, along with the significantly lower NRS score at $8 \mathrm{~h}$ after surgery. This may be because dexmedetomidine can act on the $\alpha_{2}$ receptor in the nucleus ceruleus of the brainstem to exert its sedative-hypnotic and antianxiety effects and relieve the patient's stress; also, it can act on the $\alpha_{2}$ receptors on the spinal cord and peripheral nerves to produce analgesic effects and enhance the analgesic effect and duration of local anesthetics (8). Also in our current study, perineural administration of $0.5 \mu \mathrm{g} / \mathrm{kg}$ dexmedetomidine + intercostal nerve block with $0.5 \%$ ropivacaine had significantly longer postoperative analgesia duration $[(14.2 \pm 1.2) \mathrm{h}]$ than intravenous infusion of dexmedetomidine $0.5 \mu \mathrm{g} / \mathrm{kg}$ combined with intercostal nerve block with $0.5 \%$ ropivacaine, along with the significantly lower NRS score at $12 \mathrm{~h}$ after surgery. The possible reasons may be as follows: (I) at the level of the spinal cord, dexmedetomidine acts on the $\alpha_{2}$ receptors on both presynaptic and postsynaptic membranes, inhibiting the release of adrenaline; also, it acts on the $\alpha_{2}$ receptor in the spinal dorsal horn neurons, inhibiting the release of substance $\mathrm{P}$ and other pain mediators and thereby inhibiting the transmission of pain signals; (II) at the level of peripheral nerves, dexmedetomidine inhibits the production of action potentials by $\mathrm{C}$ and $\mathrm{A} \delta$ fibers, enhances the suppression of $\mathrm{Na}+$ channels by local anesthetics, and blocks the conduction of excitation; (III) dexmedetomidine acts on the $\alpha_{2}$ receptors in peripheral vascular smooth muscle cells to constrict the peripheral blood vessels, reduce the absorption of local anesthetics, and prolong the block time $(7,9)$.

The effects of dexmedetomidine on the cardiovascular 
system are shown as the lowered HR and hypotension, which is related to the dose and infusion speed of dexmedetomidine. Thus, it must be used with caution in patients with severe ventricular dysfunction or severe atrioventricular block (10). Although no patient in our current study experienced severe hypotension or bradycardia, ephedrine and atropine were prepared during the surgery to prevent the occurrence of hypotension and bradycardia.

\section{Conclusions}

Both two administration modes of dexmedetomidine with ropivacaine for intercostal nerve block can prolong the duration of analgesia after lumpectomy; however, the duration of analgesia is longer via the perineural route than via the intravenous route.

\section{Acknowledgments}

Funding: None.

\section{Footnote}

Conflicts of Interest: All authors have completed the ICMJE uniform disclosure form and declare: The authors have no conflicts of interest to declare.

Ethical Statement: The authors are accountable for all aspects of the work in ensuring that questions related to the accuracy or integrity of any part of the work are appropriately investigated and resolved. This study was approved by the Ethics Committee of Wuxi Maternity and Child Health Care Hospital (No. 2020-06-0120-01), and all the subjects and their families signed the informed consent forms.

Open Access Statement: This is an Open Access article distributed in accordance with the Creative Commons Attribution-NonCommercial-NoDerivs 4.0 International License (CC BY-NC-ND 4.0), which permits the noncommercial replication and distribution of the article with the strict proviso that no changes or edits are made and the original work is properly cited (including links to both the formal publication through the relevant DOI and the license). See: https://creativecommons.org/licenses/by-nc-nd/4.0/.

\section{References}

1. Wang WW, Zhou WD, Wang X. The effect of the ultrasound-guided intercostal nerve block in the unilateral lumpectomy. J Clin Anesth 2015;31:763-5.

2. Wang ML, Hung MH, Hsu HH, et al. Non-intubated thoracoscopic surgery for lung cancer in patients with impaired pulmonary function. Ann Transl Med 2019;7:40.

3. Hwang JH, Chang IS, Park SW, et al. Sole use of dexmedetomidine for sedation and analgesia in patients undergoing endovenous thermal ablation for incompetent saphenous veins. Ann Transl Med 2019;7:638.

4. Liu L, Qian J, Shen B, et al. Intrathecal dexmedetomidine can decrease the $95 \%$ effective dose of bupivacaine in spinal anesthesia for cesarean section: A prospective, double-blinded, randomized study. Medicine (Baltimore) 2019;98:e14666 .

5. Andersen JH, Jaeger P, Grevstad U, et al. Systemic dexmedetomidine is not as efficient as perineural dexmedetomidine in prolonging an ulnar nerve block. Reg Anesth Pain Med 2019. [Epub ahead of print].

6. Koraki E, Stachtari C, Kapsokalyvas I, Stergiouda Z, Katsanevaki A, Trikoupi A. Dexmedetomidine as an adjuvant to $0.5 \%$ ropivacaine in ultrasound-guided axillary brachial plexus block. J Clin Pharm Ther 2018;43:348-52 .

7. Yu L, Sheng L, Hang DY, et al. Effects of different doses of dexmedetomidine on the effectiveness of intercostal nerve block with ropivacaine. Journal of Clinical Anesthesiology 2016;32:1217-8.

8. Nguyen V, Tiemann D, Park E, et al. Alpha-2 Agonists. Anesthesiol Clin 2017;35:233-45 .

9. Hou YY, Wen QP. Novel approaches of dexmedetomidine using in intravertebral anesthesia. International Journal of Anesthesiology and Resuscitation 2014;35:735-8.

10. Wu XM, Xue ZG, Ma H, et al. Expert consensus on the clinical use of dexmedetomidine (2018). Journal of Clinical Anesthesiology 2018;34:820-3.

Cite this article as: Yao F, Xu S, Zhang W, Xiong H, Han J, Zhu A. Impacts of different administration modes of dexmedetomidine with $0.5 \%$ ropivacaine on intercostal nerve block. Ann Palliat Med 2020;9(2):447-450. doi: 10.21037/ apm.2020.03.25 